\title{
Sentinel surveillance of Lyme disease risk in Canada, 2019: Results from the first year of the Canadian Lyme Sentinel Network (CaLSeN)
}

\begin{abstract}
Camille Guillott ${ }^{1,2 *}$, Jackie Badcock ${ }^{3}$, Katie Clow ${ }^{4}$, Jennifer Cram ${ }^{5}$, Shaun Dergousoff ${ }^{6}$, Antonia Dibernardo ${ }^{7}$, Michelle Evason ${ }^{6,8}$, Erin Fraser ${ }^{9,10}$, Eleni Galanis ${ }^{11}$, Salima Gasmi ${ }^{12}$, Greg J German ${ }^{13}$, Douglas T Howse ${ }^{14}$, Claire Jardine ${ }^{6}$, Emily Jenkins ${ }^{15}$, Jules Koffi ${ }^{13}$, Manisha Kulkarni ${ }^{16}$, L Robbin Lindsay ${ }^{8}$, Genevieve Lumsden ${ }^{6}$, Roman McKay ${ }^{17}$, Muhammad Morshed ${ }^{12}$, Douglas Munn ${ }^{18}$, Mark Nelder ${ }^{19}$, Joe Nocera ${ }^{19}$, Marion Ripoche ${ }^{20}$, Kateryn Rochon ${ }^{21}$, Curtis Russell ${ }^{20}$, Andreea Slatculescu ${ }^{17}$, Benoit Talbot ${ }^{17}$, Karine Thivierge ${ }^{22}$, Maarten Voordouw ${ }^{16}$, Catherine Bouchard ${ }^{1,23}$, Patrick Leighton ${ }^{1}$
\end{abstract}

\begin{abstract}
Background: Lyme disease is an emerging vector-borne zoonotic disease of increasing public health importance in Canada. As part of its mandate, the Canadian Lyme Disease Research Network (CLyDRN) launched a pan-Canadian sentinel surveillance initiative, the Canadian Lyme Sentinel Network (CaLSeN), in 2019.
\end{abstract}

Objectives: To create a standardized, national sentinel surveillance network providing a real-time portrait of the evolving environmental risk of Lyme disease in each province.

Methods: A multicriteria decision analysis (MCDA) approach was used in the selection of sentinel regions. Within each sentinel region, a systematic drag sampling protocol was performed in selected sampling sites. Ticks collected during these active surveillance visits were identified to species, and Ixodes spp. ticks were tested for infection with Borrelia burgdorferi, Borrelia miyamotoi, Anaplasma phagocytophilum, Babesia microti and Powassan virus

Results: In 2019, a total of 567 Ixodes spp. ticks (I. scapularis [n=550]; I. pacificus [n=10]; and I. angustus [n=7]) were collected in seven provinces: British Columbia, Manitoba, Ontario, Québec, New Brunswick, Nova Scotia and Prince Edward Island. The highest mean tick densities (nymphs $/ 100 \mathrm{~m}^{2}$ ) were found in sentinel regions of Lunenburg (0.45), Montréal (0.43) and Granby (0.38). Overall, the Borrelia burgdorferi prevalence in ticks was $25.2 \%(0 \%-45.0 \%)$. One I. angustus nymph from British Columbia was positive for Babesia microti, a first for the province. The deer tick lineage of Powassan virus was detected in one adult $I$. scapularis in Nova Scotia.

Conclusion: $\mathrm{CaLSeN}$ provides the first coordinated national active surveillance initiative for tick-borne disease in Canada. Through multidisciplinary collaborations between experts in each province, the pilot year was successful in establishing a baseline for Lyme disease risk across the country, allowing future trends to be detected and studied.
This work is licensed under a Creative Commons Attribution 4.0 Internationa License.

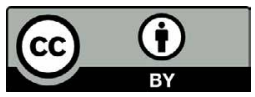

Affiliations

* See full list of affiliations in the Appendix

${ }^{\star}$ Correspondence: camille.guillot@umontreal.ca

Suggested citation: Guillot C, Badcock J, Clow K, Cram J, Dergousoff S, Dibernardo A, Evason M, Fraser E, Galanis E, Gasmi S, German GJ, Howse DT, Jardine C, Jenkins E, Koffi J, Kulkarni M, Lindsay LR, Lumsden G, McKay R, Morshed M, Munn D, Nelder M, Nocera J, Ripoche M, Rochon K, Russell C, Slatculescu A, Talbot B, Thivierge K, Voordouw M, Bouchard C, Leighton P. Sentinel surveillance of Lyme disease risk in Canada, 2019: Results from the first year of the Canadian Lyme Sentinel Network (CaLSeN). Can Commun Dis Rep 2020;46(10):354-61. https://doi.org/10.14745/ccdr.v46i10a08

Keywords: Lyme disease, sentinel surveillance, Ixodes tick, Borrelia, Canadian Lyme Disease Research Network (CLyDRN) 


\section{Introduction}

In Canada, Lyme disease is an emerging vector-borne zoonotic disease of increasing public health importance (1). Lyme disease is caused by the bacterium Borrelia burgdorferi and is primarily transmitted to humans by the blacklegged tick (Ixodes scapularis) in central and eastern Canada and the western blacklegged tick (Ixodes pacificus) in British Columbia. Since Lyme disease became a nationally notifiable disease in 2009 , the number of cases confirmed annually has risen from 144 to over 2,000 in $2017(2,3)$.

In response to the increasing risk of Lyme disease to the Canadian population and ongoing knowledge gaps, the Canadian Institutes of Health Research (CIHR) funded the creation of a national research network on Lyme disease (4). Launched in 2018, the Canadian Lyme Disease Research Network (CLyDRN) is a multidisciplinary initiative bringing together patients, physicians, social scientists, veterinarians and academic and government researchers with a patient-centred approach focused on improving the diagnosis, surveillance, prevention and treatment of Lyme disease in Canada. A key objective of the network is to better understand the risk of Lyme disease across the country and how this risk is evolving. Thus, one of the first actions of the network was to establish a pan-Canadian surveillance structure to collect comparable data about environmental risk across the country.

An important consideration in the planning of surveillance is that the risk of Lyme disease is not uniform across the country (5). This is largely due to regional differences in tick species and environments (6-9) and the uneven pattern of ongoing range expansion of $I$. scapularis populations in Canada (10). Regional differences in socioeconomic status of Canadians are also likely to influence how environmental risk affects regional incidence of Lyme disease cases (11).

While considerable effort has been invested in the measurement of Lyme disease risk for Canadians, surveillance remains heterogeneous across the country. Passive surveillance, the submission of ticks collected on humans or animals, provides valuable information on risk $(12,13)$, but cannot be maintained uniformly across the country due to resource limitations. Active surveillance, the collection of ticks from the environment by drag sampling or rodent capture, is resource-intensive and is carried out in each province according to region-specific objectives, sampling protocols and funding availability.

Here we report the first results from the Canadian Lyme Sentinel Network (CaLSeN), a new pan-Canadian LD surveillance network launched by CLyDRN in 2019. In this pilot year, we carried out standardized active surveillance of ticks in the environment across Canada using a sentinel surveillance approach. Sentinel surveillance has the advantage of concentrating surveillance effort in selected sentinel regions, providing a comparable measure of environmental risk for Lyme disease and other tick-borne diseases across the country and in-depth risk information that is complementary to ongoing federal and provincial surveillance activities.

\section{Objectives}

With surveillance carried out annually in sentinel regions in each Canadian province, the objectives of CaLSeN aim to: 1) provide the first standardized, national, real-time portrait of evolving environmental Lyme disease risk in Canada and 2) support research on regional variation in risk and its determinants.

\section{Methods}

\section{Sentinel region selection}

Sentinel regions were selected by CLyDRN's Surveillance Working Group, a group of tick-borne disease surveillance experts from both academic and public health settings. Sentinel regions were defined geographically as the area within a $25 \mathrm{~km}$ radius around the geographic centre of a selected focal municipality. The Surveillance Working Group used a multicriteria decision analysis (MCDA) approach to prioritize one to four initial sentinel regions in each province, with the objective of including additional regions over time (14).

Selection criteria included evidence of the emergence of Lyme disease based on existing passive surveillance data (number of Ixodes tick submissions/100,000 people) (10); human population covered by the network; and logistical criteria associated with field sampling and suitability of the environment for Ixodes ticks, such as presence of deciduous or mixed forests. Sentinel regions were not established in Yukon, the Northwest Territories, Nunavut or the mainland portion of Newfoundland and Labrador because current environmental conditions at these latitudes are not suitable for Ixodes spp. ticks to establish (15).

\section{Tick collection}

Ticks were collected in each sentinel region using a standardized drag sampling protocol $(16,17)$. This involved dragging a $1 \mathrm{~m} \times 1 \mathrm{~m}$ piece of white flannel cloth over $2,000 \mathrm{~m}^{2}$ of ground vegetation in linear transects, stopping every $25 \mathrm{~m}$ to collect questing ticks that had clung to the passing cloth. Multiple sampling sites were selected in each sentinel region. Locations were chosen because they had suitable tick habitats. Surveillance efforts were increased in known Lyme disease-endemic areas to obtain fine-scale information on the distribution of risk within these areas (Table 1). Each site was sampled once during the summer (May-August 2019), targeting the regional peak in activity of nymphal Ixodes spp. ticks, the stage of greatest public health significance (18-20). In addition to collecting ticks, we collected data on leaf litter depth, canopy cover and soil humidity at each sampling location and noted ambient temperature and weather conditions during collection to account for the possible effects of these variables on tick collection. 
Table 1: Density of Ixodes spp. nymphs collected across all sampling sites within each sentinel region of the Canadian Lyme Sentinel Network, 2019

\begin{tabular}{|c|c|c|c|c|c|}
\hline \multirow{2}{*}{ Sentinel region } & \multirow{2}{*}{$\begin{array}{l}\text { No. of sites } \\
\text { visited (n) }\end{array}$} & \multicolumn{3}{|c|}{ Density (no. of nymphs / $100 \mathrm{~m}^{2}$ ) } & \multirow{2}{*}{ Standard deviation } \\
\hline & & Minimum & Maximum & Mean & \\
\hline Vancouver, BC & 5 & 0 & 0.10 & 0.04 & 0.04 \\
\hline Lethbridge, $A B$ & 3 & 0 & 0 & 0 & 0 \\
\hline Saskatoon, SK & 3 & 0 & 0 & 0 & 0 \\
\hline Winnipeg, MB & 5 & 0 & 0 & 0 & 0 \\
\hline Hamilton, ON & 5 & 0 & 0.1 & 0.02 & 0.04 \\
\hline Kingston, ON & 15 & 0.05 & 1.15 & 0.27 & 0.38 \\
\hline Ottawa-Gatineau, ON/OC & 10 & 0 & 0.4 & $0.06^{a}$ & 0.12 \\
\hline Montréal, QC & 10 & 0 & 2.90 & 0.43 & 0.91 \\
\hline Granby, QC & 5 & 0 & 1.15 & 0.38 & 0.48 \\
\hline Sherbrooke, QC & 5 & 0 & 0 & 0 & 0 \\
\hline Saint John, NB & 5 & 0 & 0.30 & 0.09 & 0.13 \\
\hline Charlottetown, PEI & 5 & 0 & 0.05 & 0.01 & 0.02 \\
\hline Lunenburg, NS & 10 & 0 & 2.45 & 0.45 & 0.74 \\
\hline St. John's, NL & 5 & 0 & 0 & 0 & 0 \\
\hline
\end{tabular}

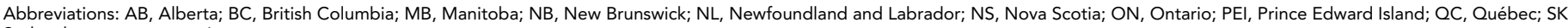
Saskatchewan; spp., species

a Site visits in the Ottawa-Gatineau region were conducted in early June, prior to the peak in nymphal tick abundance. Thus, reported densities may not be representative of densities later in the summer

\section{Laboratory analyses}

The species of all ticks collected by drag sampling were identified, but only I. scapularis ( $n=550)$, I. pacificus $(n=10)$ and I. angustus $(n=7)$ were tested for the presence of pathogens as they are known vectors for $B$. burgdorferi and other pathogens. Individual ticks were tested for the presence of Anaplasma phagocytophilum, Babesia microti, B. burgdorferi, Borrelia miyamotoi and Powassan virus by real-time polymerase chain reaction (PCR) or reverse transcriptase-PCR with slight modifications to previously described methods (21). Briefly, nucleic acids were extracted from ticks using OIAGEN RNeasy 96 kits (QIAGEN Inc., Mississauga, Ontario, Canada). The extracts contained both RNA and DNA, and were screened for all the pathogens listed above. Modifications to testing algorithms included the use of an in-house triplex screening assay targeting the 18S rRNA gene of Babesia species, followed by the $B$. microti-specific CCT-eta real-time assay for confirmation, as well as a duplex assay (22) to confirm the presence of $B$. burgdorferi and/or B. miyamotoi.

\section{Statistical analyses}

Results are presented as descriptive statistics. We used a paired Wilcoxon test to compare mean Borrelia prevalence in adult and nymphal ticks. Analyses were conducted using $\mathrm{R}$ version 3.6.2 (23).

\section{Results}

\section{Sentinel regions and sampling sites}

In total, 96 sites in 14 sentinel regions (Figure 1) were sampled from 22 May 2019 to 20 August 2019, with three to 15 sampling sites per region (Table 1).

\section{Ixodes spp. ticks}

A total of 567 Ixodes spp. ticks were collected in 10 sentinel regions in seven provinces: British Columbia, Manitoba, Ontario, Québec, New Brunswick, Nova Scotia and Prince Edward Island. I. pacificus $(n=10)$ and $I$. angustus $(n=7)$ ticks were collected exclusively in Vancouver, British Columbia. I. scapularis ticks $(n=550)$ were collected in Manitoba, Ontario, Québec, New Brunswick, Nova Scotia and Prince Edward Island.

Nymphs were collected in each of these provinces, except for Manitoba (Winnipeg) where only adults were collected (Figure 2). Mean density of nymphs (nymphs $/ 100 \mathrm{~m}^{2}$ [SD]), which pose the greatest risk of infection to humans, was highest in the sentinel regions of Lunenburg $(0.45$ [0.74]), Montréal $(0.43$ [0.91]), Granby (0.38 [0.48]) and Kingston (0.27 [0.38]) (Table 1). The Ottawa-Gatineau region was sampled early in the season, yielding a lower density of nymphs $(0.06$ [0.12]) but a high density of adults (0.42 [0.72]), which also pose a significant health risk. 
Figure 1: Location of sentinel regions in the Canadian Lyme Sentinel Network in 2019a,b

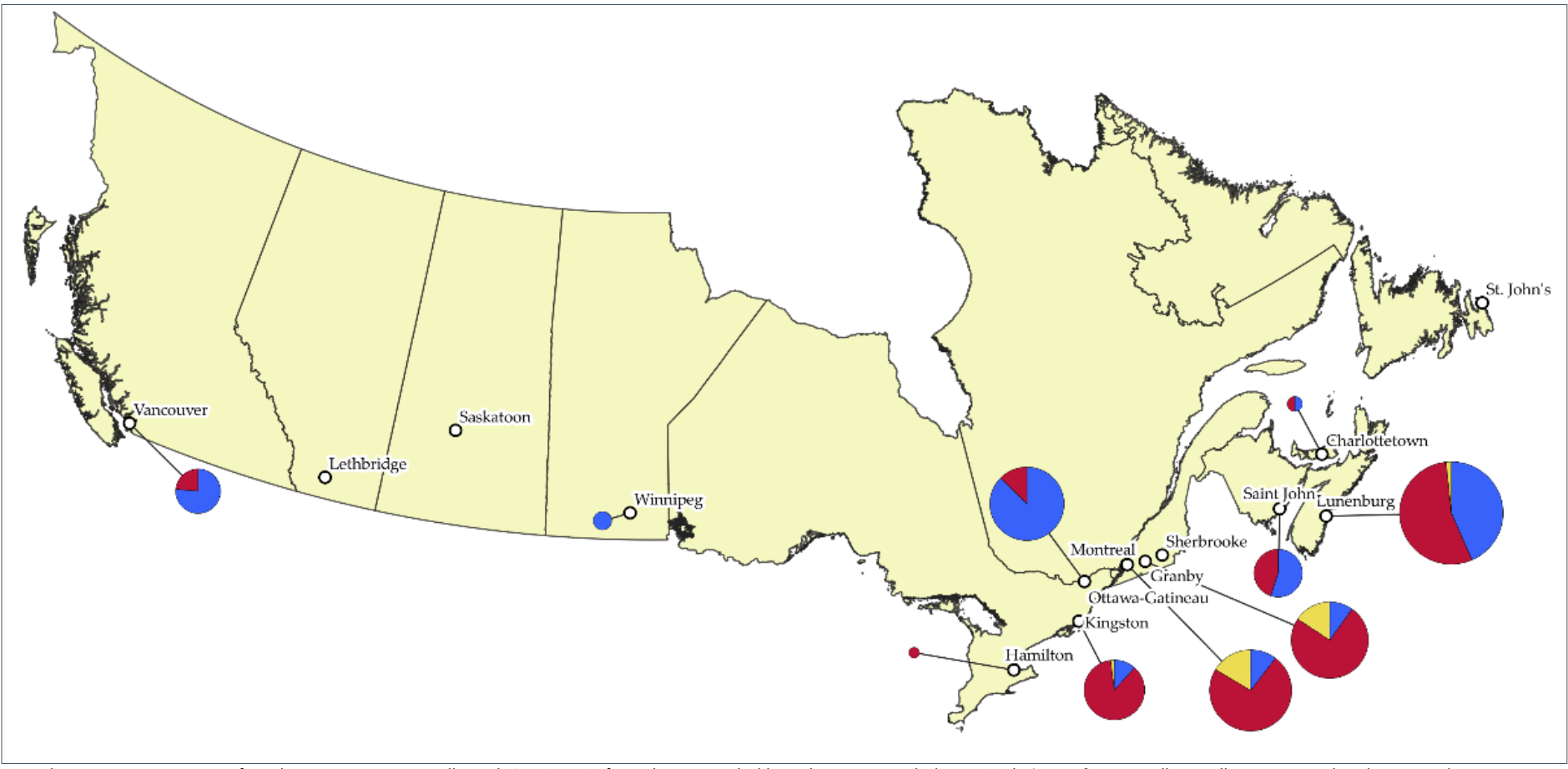

a Pie charts represent stages of Ixodes spp. specimens collected. Size (area) of pie charts is scaled linearly to mean tick density (ticks/100 $\mathrm{m}^{2}$ ) across all surveillance sites within the sentinel region b Yellow (larva); red (nymphs); blue (adults)

Figure 2: Ixodes spp. tick densities by stage (larva, nymph and adult) for each sentinel region in the Canadian Lyme Sentinel Network in 2019

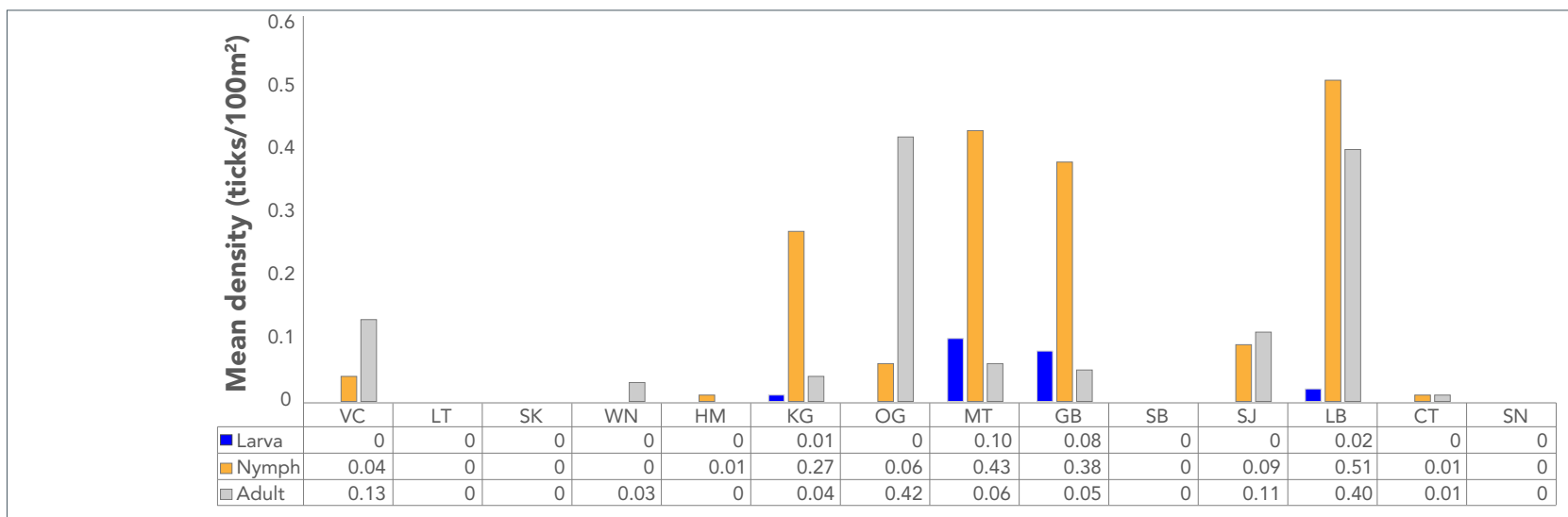

Sentinel region

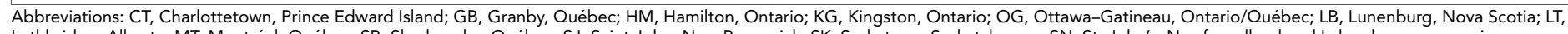

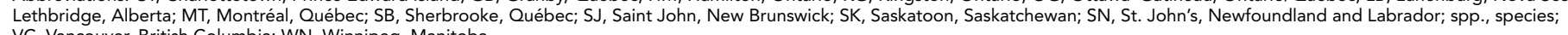
VC, Vancouver, British Columbia; WN, Winnipeg, Manitoba

\section{Laboratory analyses}

B. burgdorferi infection prevalence in all lxodes ticks (nymphs and adults) ranged from $0 \%$ to $45 \%$ (Table 2). Mean infection prevalence was higher in adult ticks $(36.3 \%)$ than nymphal ticks (22.0\%), but this difference was not statistically significant (paired Wilcoxon test; $P=0.142 ; V=3$ ). B. miyamotoi was found in two specimens, one from Ottawa-Gatineau and the other from Montréal. A. phagocytophilum infection prevalence varied from $0 \%$ to $4.1 \%$ in sentinel regions where $I$. scapularis ticks were found. B. microti was found in one I. angustus tick in the Vancouver sentinel region. One adult $I$. scapularis was positive for Powassan virus in the Lunenburg sentinel region. 
Table 2: Ixodes spp. tick abundance in sentinel regions of the Canadian Lyme Sentinel Network in 2019 and infection prevalence of tick-borne pathogens

\begin{tabular}{|c|c|c|c|c|c|c|c|c|c|c|c|}
\hline \multirow{2}{*}{ Sentinel region } & \multicolumn{4}{|c|}{ Ixodes spp. abundance (n) } & \multicolumn{7}{|c|}{ Infection prevalence $(\%)^{a, b}$} \\
\hline & Larva & Nymph & Adult & Total & BbN & BbA & $\mathrm{BbT}$ & $\mathrm{Bm}$ & Ap & Bmi & POWV \\
\hline Vancouver, BC & 0 & 4 & 13 & 17 & $0^{c}$ & $0^{c}$ & $0^{c}$ & $0^{c}$ & $0^{c}$ & $5.9^{e}$ & $0^{c}$ \\
\hline Lethbridge, $A B$ & 0 & 0 & 0 & 0 & NA & NA & NA & NA & NA & NA & NA \\
\hline Saskatoon, SK & 0 & 0 & 0 & 0 & NA & NA & NA & NA & NA & NA & NA \\
\hline Winnipeg, MB & 0 & 0 & 3 & 3 & NA & $0^{c}$ & $0^{c}$ & $0^{c}$ & $0^{c}$ & $0^{c}$ & $0^{c}$ \\
\hline Hamilton, ON & 0 & 2 & 0 & 2 & $0^{c}$ & $0^{c}$ & $0^{c}$ & $0^{c}$ & $0^{c}$ & $0^{c}$ & $0^{c}$ \\
\hline Kingston, ON & 2 & 82 & 11 & 95 & $28.0^{f}$ & $54.5^{f}$ & $31.2^{f}$ & $0^{c}$ & $1.1^{d}$ & $0^{c}$ & $0^{c}$ \\
\hline Ottawa-Gatineau, ON/OC & 0 & 12 & 83 & 95 & $33.3^{f}$ & $39.8^{f}$ & $38.9^{f}$ & $1.1^{\mathrm{d}}$ & $0^{c}$ & $0^{c}$ & $0^{c}$ \\
\hline Montréal, QC & 19 & 85 & 12 & 116 & $14.1^{\mathrm{e}}$ & $66.7^{f}$ & $20.6^{f}$ & $1.0^{\mathrm{d}}$ & $1.0^{d}$ & $0^{c}$ & $0^{c}$ \\
\hline Granby, OC & 3 & 37 & 5 & 45 & $13.5^{e}$ & $60^{f}$ & $19.0^{e}$ & $0^{c}$ & $2.4^{d}$ & $0^{c}$ & $0^{c}$ \\
\hline Sherbrooke, OC & 0 & 0 & 0 & 0 & NA & NA & NA & NA & NA & NA & NA \\
\hline Saint John, NB & 0 & 9 & 11 & 20 & $55.6^{f}$ & $36.4^{f}$ & $45^{f}$ & $0^{c}$ & $5^{e}$ & $0^{c}$ & $0^{c}$ \\
\hline Charlottetown, PEI & 0 & 1 & 1 & 2 & $0^{c}$ & $0^{c}$ & $0^{c}$ & $0^{c}$ & $0^{c}$ & $0^{c}$ & $0^{c}$ \\
\hline Lunenburg, NS & 3 & 96 & 73 & 172 & $24.0^{f}$ & $31.5^{f}$ & $26.6^{f}$ & $0^{c}$ & $4.1^{d}$ & $0^{c}$ & $0.6^{d}$ \\
\hline St. John's, NL & 0 & 0 & 0 & 0 & NA & NA & NA & NA & NA & NA & NA \\
\hline Total number & 27 & 328 & 212 & 567 & NA & NA & NA & NA & NA & NA & NA \\
\hline Overall prevalence & NA & NA & NA & NA & 22.0 & 36.3 & 26.6 & $<0.01$ & 0.02 & $<0.01$ & $<0.01$ \\
\hline
\end{tabular}

Abbreviations: AB, Alberta; Ap, Anaplasma phagocytophilum; BbA, Borrelia burgdorferi infection prevalence in adult ticks; BbN Borrelia burgdorferi infection prevalence in nymphal ticks;

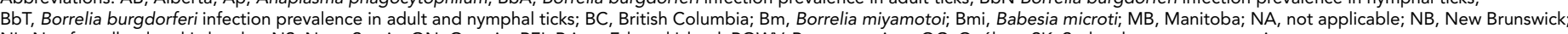

NL, Newfoundland and Labrador; NS, Nova Scotia; ON, Ontario; PEI, Prince Edward Island; POWV, Powassan virus; QC, Québec; SK, Saskatchewan; spp., species

anly adult and nymphal Ixodes spp. ticks were tested

Infection prevalence presented as tick numbers in some sentinel regions are too small to infer a prevalence rate

Zero (green) no infected ticks

Infection prevalence $<5 \%$ (blue)

Infection prevalence $5 \%-20 \%$ (yellow)

${ }^{f}$ Infection prevalence $>20 \%$ (red)

\section{Discussion}

In its pilot year, the Canadian Lyme Sentinel Network

documented the presence of Ixodes tick species that are vectors of $B$. burgdorferi and four other human pathogens in seven out of 10 Canadian provinces, with an overall infection prevalence of $25.2 \%(0 \%-45.0 \%)$ for $B$. burgdorferi. However, we noted a great variability between regions: while no Borrelia were found in British Columbia, Prince Edward Island or Manitoba, infection prevalence in sentinel regions in Ontario, Québec, New Brunswick and Nova Scotia ranged between 19.0\% and $45.0 \%$. These results align with the results of recent studies of the distribution of I. scapularis ticks in Canada (24-27), suggesting that the sentinel approach adopted by CaLSeN is successfully capturing regional variations in Lyme disease risk.

Surveillance results highlighted notable regional variation in density of $I$. scapularis within Ontario and Québec. Mean density of nymphs in the Granby and Montréal regions of Québec were 0.38 and 0.43 ticks per $100 \mathrm{~m}^{2}$, respectively, whereas no blacklegged ticks were found in Sherbrooke. In Ontario, nymph densities were high in Kingston (0.27 nymphs/100 m²), but much lower in southern Ontario, with only 0.02 nymphs $/ 100 \mathrm{~m}^{2}$ in
Hamilton. Nymph densities from Ottawa should be interpreted with caution, as sampling was undertaken earlier in the summer, prior to the summer peak in nymph activity.

The 2019 surveillance by CaLSeN represents the first effort to detect locally reproducing populations of I. scapularis ticks through active surveillance in both Prince Edward Island and the island of Newfoundland. Thus, the presence of I. scapularis confirmed by drag sampling in Prince Edward Island was a novel finding. The detection of two different stages (nymph and adult) in the environment at two separate sampling sites is early evidence that local reproduction of ticks may be occurring. However, it is possible that the two specimens were adventitious ticks carried to the island by migrating birds. Further active surveillance will be necessary to confirm whether ticks are established in the province.

Laboratory analyses of collected ticks yielded two noteworthy pathogen detections. Firstly, B. microti was detected in an I. angustus nymph, the first report of a tick infected with this pathogen in British Columbia. Secondly, the deer tick lineage of Powassan virus was detected in the Lunenburg sentinel region and this is only the second detection of this pathogen in questing ticks in the region (28). 


\section{Strengths and limitations}

A major strength of our surveillance network is the collaboration established between provinces and between public health authorities and academics. These links have allowed knowledge translation between the involved parties and have been crucial during the planning phases of the network. Partnership was essential during the selection of sentinel regions and in carrying out the fieldwork. To strengthen these collaborations, CaLSeN will continue to work closely with provincial health authorities to ensure that the activities of the network are complementary to and coordinated with provincial surveillance objectives.

An important limitation to the interpretation of results is the variable timing of the sampling in each region. This may have contributed to differences in the abundance of the tick stages collected, as adults are generally active earlier in the spring whereas nymphal abundance peaks slightly later in the summer (29). The absolute values of reported tick densities therefore need to be interpreted with caution.

The inclusion of variables such as temperature and weather during the sampling event in further statistical analyses carried out on gathered data will also be important to control for variability in timing of tick sampling. Finally, pursuing yearly sampling within a time-frame more closely aligned with the peak in nymphal activity will provide better data for documenting change in regional risk over time.

\section{Conclusion}

The Canadian Lyme Sentinel Network provides the first coordinated national active surveillance initiative for tick-borne disease in Canada. To our knowledge, the sentinel surveillance approach has not been applied to Lyme disease on the national scale elsewhere in North America or Europe, making CaLSeN a useful model for other countries affected by Lyme disease and other tick-borne illnesses. Following the establishment of baseline data on Lyme disease vectors and prevalence of Borrelia, an important next step will be to establish the link between the environmental risk and the regional incidence of human cases. Further collection of environmental, social and human case data across sentinel regions will allow for the exploration of the broader representativity of sentinel-based risk measures for tick-borne disease surveillance.

\section{Authors' statement}

CG - Conceptualization, methodology, analysis, interpretation, writing original draft, review and editing

PAL - Conceptualization, methodology, interpretation, review and editing

CB, KC, SG, CJ, JK, MK, LRL, RM, MN, MR, CR, AS, BT -

Methodology, interpretation, review and editing

$J B, A D, S D, M E, E F, E G, G G, D H, E J, G L, D M, M M, J N, K R, K T$, $\mathrm{MV}$ - Methodology

\section{Competing interests}

None.

\section{Acknowledgements}

We thank the many field and laboratory technicians who were involved in tick collection and testing. We gratefully acknowledge the support of regional and provincial health authorities in facilitating site selection, and regional and national parks for providing access to field sites.

\section{Funding}

This work was supported by the Canadian Lyme Disease Research Network (CLyDRN), a network funded by the Canadian Institutes of Health Research (CIHR). The Institut national de santé publique du Québec (INSPQ) and Ministère de la santé et des services sociaux (MSSS) funded data collection in 12 sampling sites within Québec sentinel regions as part of annual surveillance activities. The National Microbiology Laboratory confirmed the species determinations and undertook the testing of ticks for tick-associated pathogens for specimens collected in all jurisdictions outside of Ontario.

\section{References}

1. Kulkarni MA, Berrang-Ford L, Buck PA, Drebot MA, Lindsay LR, Ogden NH. Major emerging vector-borne zoonotic diseases of public health importance in Canada. Emerg Microbes Infect 2015;4(6):e33-e. DOI

2. Surveillance of Lyme disease. Ottawa (ON): Government of Canada (accessed 2020-03-02). www.canada.ca/ en/public-health/services/diseases/lyme-disease/ surveillance-lyme-disease.html

3. Gabriele-Rivet V, Arsenault J, Badcock J, Cheng A, Edsall J, Goltz J, Kennedy J, Lindsay LR, Pelcat Y, Ogden NH. Different ecological niches for ticks of public health significance in Canada. PLoS One 2015 Jul;10(7):e0131282. DOI PubMed

4. Canadian Lyme Disease Research Network. 2019. Interested in our work? CLyDRN; 2019 (accessed 2020-03-02). https://www. clydrn.ca/

5. Ogden NH, Bouchard C, Badcock J, Drebot MA, Elias SP, Hatchette TF, Koffi JK, Leighton PA, Lindsay LR, Lubelczyk CB, Peregrine AS, Smith RP, Webster D. What is the real number of Lyme disease cases in Canada? BMC Public Health 2019 Jun;19(1):849. DOI PubMed

6. Ogden $\mathrm{NH}$, Lindsay LR, Morshed M, Sockett PN, Artsob $\mathrm{H}$. The emergence of Lyme disease in Canada. CMAJ 2009 Jun;180(12):1221-4. DOI PubMed 
7. Ogden $\mathrm{NH}$, Maarouf A, Barker IK, Bigras-Poulin M, Lindsay LR, Morshed MG, O'callaghan CJ, Ramay F, Waltner-Toews $D$, Charron DF. Climate change and the potential for range expansion of the Lyme disease vector Ixodes scapularis in Canada. Int J Parasitol 2006 Jan;36(1):63-70. DOI PubMed

8. Kulkarni MA, Narula I, Slatculescu AM, Russell C. Lyme disease emergence after invasion of the blacklegged tick, lxodes scapularis, Ontario, Canada, 2010-2016. Emerg Infect Dis 2019 Feb;25(2):328-32. DOI PubMed

9. Gasmi S, Bouchard C, Ogden NH, Adam-Poupart A, Pelcat Y, Rees EE, Milord F, Leighton PA, Lindsay RL, Koffi JK, Thivierge K. Evidence for increasing densities and geographic ranges of tick species of public health significance other than Ixodes scapularis in Québec, Canada. PLoS One 2018 Aug;13(8):e0201924. DOI PubMed

10. Leighton P, Koffi J, Pelcat $Y$, Lindsay R, Ogden N. Predicting the speed of tick invasion: an empirical model of range expansion for the Lyme disease vector Ixodes scapularis in Canada. J Appl Ecol 2012;49(2):457-64. DOI

11. Aenishaenslin C, Michel P, Ravel A, Gern L, Milord F, Waaub JP, Bélanger $D$. Factors associated with preventive behaviors regarding Lyme disease in Canada and Switzerland: a comparative study. BMC Public Health 2015 Feb;15(1):185. DOI PubMed

12. Ripoche M, Gasmi S, Adam-Poupart A, Koffi JK, Lindsay LR, Ludwig A, Milord F, Ogden NH, Thivierge K, Leighton PA. Passive tick surveillance provides an accurate early signal of emerging Lyme disease risk and human cases in southern Canada. J Med Entomol 2018 Jun;55(4):1016-26. DOI PubMed

13. Koffi JK, Leighton PA, Pelcat Y, Trudel L, Lindsay LR, Milord F, Ogden NH. Passive surveillance for I. scapularis ticks: enhanced analysis for early detection of emerging Lyme disease risk. J Med Entomol 2012 Mar;49(2):400-9. DOI PubMed

14. Frazão TD, Camilo DG, Cabral EL, Souza RP. Multicriteria decision analysis (MCDA) in health care: a systematic review of the main characteristics and methodological steps. BMC Med Inform Decis Mak 2018 Nov;18(1):90. DOI PubMed

15. Ogden NH, Radojevic M, Wu X, Duvvuri VR, Leighton PA, Wu J. Estimated effects of projected climate change on the basic reproductive number of the Lyme disease vector Ixodes scapularis. Environ Health Perspect 2014 Jun;122(6):631-8. DOI PubMed

16. Diuk-Wasser MA, Hoen AG, Cislo P, Brinkerhoff R, Hamer SA, Rowland M, Cortinas R, Vourc'h G, Melton F, Hickling GJ, Tsao JI, Bunikis J, Barbour AG, Kitron U, Piesman J, Fish D. Human risk of infection with Borrelia burgdorferi, the Lyme disease agent, in eastern United States. Am J Trop Med Hyg 2012 Feb;86(2):320-7. DOI PubMed

17. Clow KM, Finer R, Lumsden G, Jardine CM. Assessing the repeatability of tick dragging as a method for Ixodes scapularis surveillance. Vector Borne Zoonotic Dis 2018 Nov; 18(11):62831. DOI PubMed

18. Stafford KC III, Cartter ML, Magnarelli LA, Ertel SH, Mshar PA. Temporal correlations between tick abundance and prevalence of ticks infected with Borrelia burgdorferi and increasing incidence of Lyme disease. J Clin Microbiol 1998 May;36(5):1240-4. DOI PubMed
19. Mather TN, Nicholson MC, Donnelly EF, Matyas BT. Entomologic index for human risk of Lyme disease. Am J Epidemiol 1996 Dec;144(11):1066-9. DOI PubMed

20. Pepin KM, Eisen RJ, Mead PS, Piesman J, Fish D, Hoen AG, Barbour AG, Hamer S, Diuk-Wasser MA. Geographic variation in the relationship between human Lyme disease incidence and density of infected host-seeking lxodes scapularis nymphs in the Eastern United States. Am J Trop Med Hyg 2012 Jun;86(6):1062-71. DOI PubMed

21. Schillberg E, Lunny D, Lindsay LR, Nelder MP, Russell C, Mackie M, Coats D, Berry A, Young Hoon KN. Distribution of Ixodes scapularis in northwestern Ontario: Results from active and passive surveillance activities in the Northwestern Health Unit Catchment Area. Int J Environ Res Public Health 2018 Oct;15(10):2225. DOI PubMed

22. Tokarz R, Tagliafierro T, Cucura DM, Rochlin I, Sameroff S, Lipkin WI. Detection of Anaplasma phagocytophilum, Babesia microti, Borrelia burgdorferi, Borrelia miyamotoi, and Powassan virus in ticks by a multiplex real-time reverse transcription-PCR assay. MSphere 2017 Apr;2(2):e00151-17. DOI PubMed

23. R Core Team. R: A language and environment for statistical computing. Vienna (AT): R Foundation for Statistical Computing; 2019 (accessed 2020-03-02). https://www.R-project.org/

24. Gasmi S, Ogden NH, Ripoche M, Leighton PA, Lindsay RL, Nelder MP, Rees E, Bouchard C, Vrbova L, Rusk R, Russell C, Pelcat Y, Mechai S, Kotchi SO, Koffi JK. Detection of municipalities at-risk of Lyme disease using passive surveillance of Ixodes scapularis as an early signal: A province-specific indicator in Canada. PLoS One 2019 Feb;14(2):e0212637. DOI PubMed

25. Villeneuve A, Goring J, Marcotte L, Overvelde S. Seroprevalence of Borrelia burgdorferi, Anaplasma phagocytophilum, Ehrlichia canis, and Dirofilaria immitis among dogs in Canada. Can Vet J 2011 May;52(5):527-30. PubMed

26. Ouhoummane N, Adam-Poupart A, Milord F, Irace-Cima A, Thivierge K, Therrien C. Report on surveillance for Lyme disease: 2016. Quebec (QC): Institut national de santé publique du Québec; 2017. https://www.inspq.qc.ca/publications/2296

27. Clow KM, Ogden NH, Lindsay LR, Michel P, Pearl DL, Jardine CM. Distribution of ticks and the risk of Lyme disease and other tick-borne pathogens of public health significance in Ontario, Canada. Vector Borne Zoonotic Dis 2016 Apr;16(4):215-22. DOI PubMed

28. Tick borne diseases response plan: May 2020. Halifax (NS): Province of Nova Scotia; 2020-05-12 (accessed 202008-27). https://novascotia.ca/dhw/cdpc/documents/ Tick-Borne-Disease-Response-Plan.pdf

29. Rodgers SE, Miller NJ, Mather TN. Seasonal variation in nymphal blacklegged tick abundance in southern New England forests. J Med Entomol 2007 Sep;44(5):898-900. DOI PubMed 


\section{Appendix: List of affiliations}

${ }^{1}$ Département de pathologie et microbiologie, and Groupe de recherche en épidémiologie des zoonoses et santé publique (GREZOSP), Faculté de médecine vétérinaire, Université de Montréal, Montréal, QC

2 Faculté de médecine et des sciences de la santé, Université de Sherbrooke, Sherbrooke, QC

${ }^{3}$ Office of the Chief Medical Officer of Health, New Brunswick Department of Health, Fredericton, NB

${ }^{4}$ Department of Pathobiology, Ontario Veterinary College, University of Guelph, Guelph, ON

${ }^{5}$ Nova Scotia Health Authority, Halifax, NS

${ }^{6}$ Agriculture and Agri-Food Canada, Lethbridge Research and Development Centre, Lethbridge, AB

${ }^{7}$ National Microbiology Laboratory, Public Health Agency of Canada, Winnipeg, MB

${ }^{8}$ Department of Companion Animals, Atlantic Veterinary College, University of Prince Edward Island, Charlottetown, PEI

${ }^{9}$ Communicable Diseases \& Immunization Service, British Columbia Centre for Disease Control, Victoria, BC

${ }^{10}$ School of Population and Public Health, Faculty of Medicine, University of British Columbia, Vancouver, BC

${ }^{11}$ Zoonotic Diseases and Emerging Pathogens, British Columbia Centre for Disease Control, Vancouver, BC

12 Policy Integration and Zoonoses Division, Centre for FoodBorne, Environmental and Zoonotic Diseases, Public Health Agency of Canada, Saint-Hyacinthe, QC
${ }^{13}$ PEI Provincial Microbiology Laboratory, Health PEI, Charlottetown, PEI

${ }^{14}$ Department of Health and Community Services, Public Health Division, St. John's, NL

${ }^{15}$ University of Saskatchewan, Saskatoon, SK

${ }^{16}$ School of Epidemiology and Public Health, University of Ottawa, Ottawa, ON

${ }^{17}$ KFL\&A Public Health, Kingston, ON

${ }^{18}$ Faculty of Forestry \& Environmental Management, University of New Brunswick, Fredericton, NB

${ }^{19}$ Enteric, Zoonotic and Vector-Borne Diseases, Communicable Diseases, Emergency Preparedness and Response, Public Health Ontario, Toronto, ON

${ }^{20}$ Surveillance, évaluation de risque et contrôle des maladies infectieuses, Institut national de santé publique du Québec, Montréal, QC

${ }^{21}$ Department of Entomology, University of Manitoba, Winnipeg, MB

22 Laboratoire de santé publique du Québec, Saint-Anne-de-Bellevue, OC

${ }^{23}$ Public Health Risk Sciences Division, National Microbiology Laboratory, Public Health Agency of Canada, Saint-Hyacinthe, QC 